\title{
SHARING RISKS OR PROLIFERATING UNCERTAINTIES?
}

\author{
Insurance, disaster and development
}

\author{
Leigh Johnson
}

\section{Introduction}

Today, anyone who is under the impression that insurance is a luxury that is only available in wealthy countries of the global North is faced with a multitude of examples to the contrary. Not only are traditional lines of insurance business, like life and health insurance, growing rapidly in much of the global South, new forms of insurance harnessing powerful geospatial monitoring and modelling technologies are increasingly being deployed to offer Southern governments insurance for hazards such as droughts, floods, cyclones and diseases. It is hoped that such coverage will secure development gains. But has the growth of such tools actually reduced uncertainties? So far, the evidence is mixed.

The actuarial technologies of the insurance industry have long been central to the development of methods to assess uncertainty. These methods yield quantifiable - and thus priceable and transferable - risk. Amid the proliferating uncertainties of climate change and the growing cost of disasters, the impulse to insure across more geographic and hazard domains has grown. Insurers and multilateral institutions now explicitly seek to narrow what they call the 'global protection gap' - the difference between total economic losses and insured losses (Lloyd's 2018; Swiss Reinsurance 2015). Development institutions and insurers have advanced several strategies to occupy this protection gap, which is widest in countries of the global South. They have advocated insurance-linked tools such as catastrophe bonds, promoted the application of insurance-based logic to new domains like pandemic diseases and launched insurance pools at new multi-country scales.

Yet almost none of these instruments look like what we imagine as traditional insurance arrangements. The large majority of these instruments are 'parametric' products, in which payouts are triggered by measured or modelled environmental variables. This chapter first explores why parametric insurance and related risk 
transfer tools are increasingly popular responses in development practice. It then argues that this embrace can paradoxically proliferate uncertainties when insurance contracts fail to pay out, illustrated with reference to drought insurance in Malawi and pandemic insurance in the Democratic Republic of Congo. The chapter closes by envisioning how insurance might be refashioned from a 'technology of hubris' to a 'technology of humility' (Jasanoff 2003), suggesting some principles for more relational deployments of insurance that could begin to recuperate its promise as a technique of mutual solidarity and sustainable risk-sharing.

\section{The impulse to insure}

There are both economic and political reasons why insurance - and disaster risk finance more broadly - have become major domains for development intervention. Given that many Southern countries have long since been compelled to remove social safety nets and market controls as a condition for continuing to receive loans from international institutions, there is often little to cushion their populations, leaving them especially vulnerable to shocks. An early World Bank piece advancing the framework of weather risk management identified the processual link between micro and macro: 'Ultimately, the precariousness of farmers and producers translates into macroeconomic vulnerability’ (Hess et al. 2002: 296). Multilateral institutions now identify disaster shocks as a major impediment to a country's macroeconomic stability and its ability to maintain the welfare of its citizens (Cummins and Mahul 2009). Disasters constitute a fiscal 'squeeze': while a government's unbudgeted relief expenditures rise, its future revenue-raising capacity deteriorates as household assets are lost and incomes decline. Declining revenues impair a government's capacity to pay off existing loans or issue bonds, forcing it to take on more emergency debt. Such dynamics are not just the concern of international financial institutions: activist organisations such as the Jubilee Debt Campaign have recently argued that climate change is intensifying these patterns, warning of 'climate debt traps' resulting from post-disaster emergency borrowing, such as the loan Mozambique took following Cyclone Idai in 2019 (Sauer 2019).

Insurance - and particularly the global insurance industry - occupies pride of place in the push to move from ex post to ex ante financing arrangements. This is partly a result of scalar relations. The difficulty of some of the thorniest problems in the field of development - large 'natural' disasters, climate change impacts and pandemic disease among them - is that they are spatially and temporally covariant. While everyday coping systems might work to buffer people from quotidian individual shocks, they are overwhelmed when many people in a region suffer from the same event at the same time. Likewise, government funds, if they exist at all, are quickly exhausted, particularly in countries with small economies. For instance, the Solomon Islands has no disaster reserves, and average annual disaster losses consume 6.5 per cent of Vanuatu's GDP (World Bank 2015: 9).

In these contexts, the large and globally diversified pools of capital held by the reinsurance industry have become a virtually indispensable element of the 
development sector's approach. In the absence of a multilateral development insurer, ${ }^{1}$ it is the reinsurance industry that can quickly dispatch the quantities of post-disaster liquidity required. This industry has also systematically cultivated actuarial and modelling expertise and positioned itself as a consummate provider of risk management solutions. Its operational framework dovetails with Western donors' mandates to make aid more auditable and economically efficient, and to deploy market-based solutions and private sector capital to bridge financing gaps (Mawdsley 2015).

Since the mid-2010s, cash-strapped humanitarian and aid agencies have faced ballooning numbers of crisis-affected populations, exacerbated by ongoing conflict, extreme weather events linked to climate change and increasingly uncertain funding streams from isolationist Western donors. This precarious situation has driven an emphasis on the dollar-for-dollar efficiency of aid and objective criteria for its disbursement. This aligns with an insurance-based approach to modelling, pricing and contractually managing risks. Formal insurance or insurance-like instruments require contractual specifications that delineate who is responsible for post-disaster transfers, for what and in what circumstances. Such specificity holds obvious appeal for improving welfare given the delays and chaos of ordinary humanitarian response - what Dunn (2012) terms 'adhocracy'.

In theory, the process of deciding what insurance coverage to purchase should encourage pre-disaster risk assessment, management and response planning. The pre-defined terms of insurance contracts should secure funding for response and delineate post-disaster responsibilities (Clarke and Dercon 2016). In turn, the automaticity of payouts based on environmental measures should secure timely financing for urgent needs and facilitate disbursement from a distance, while transparency about payout conditions should reduce perennial donor concerns about aid leakage and corruption. This, at least, is the vision.

In practice, many applications of insurance technologies have demonstrated the hazards of what science studies scholar Sheila Jasanoff (2003: 238) calls 'technologies of hubris'. By this, she refers to technologies that leverage science 'to facilitate management and control even in areas of high uncertainty ... [which] achieve their power through claims of objectivity and a disciplined approach to analysis' (ibid.). Despite the power of these technologies, their advocates are often overconfident of their accuracy and rigour, and blind to forms of uncertainty that fall outside their framing assumptions. They tend to invoke the objectivity of their expertise in order to avoid political debate and calls for social accountability. The cases of drought and pandemic insurance, to which the chapter turns next, suggest that parametric insurance is no stranger to the hazards of technological hubris.

\section{The political economy of basis risk: blame and liability}

To understand how uncertainty becomes a transferred political and economic object we need to grasp the logic of assembly behind parametric insurance tools. In ordinary indemnity-based insurance contracts, losses are inspected and the monetary 
payout made is at least ostensibly proportional to that loss. But indemnification is expensive, and requires constant work with regards to surveillance and data gathering. In contrast, most disaster risk insurance contracts now on offer are built on parametric logic. In parametric contracts, payouts are determined by the value of one or more measured environmental variable - a parameter like rainfall or pasture greenness - that can be monitored at a distance. Parametric logic posits scalar correspondence between selected variables at easily observed scales, and actual losses at less easily observed scales. Contract designers inevitably make tremendous simplifications and exclusions when postulating this correspondence.

By definition, parametric contracts must abstract from contextual conditions, setting standardised proxies that can be efficiently applied to determine payouts. These technical processes of simplification, exclusion and decontextualisation have allowed insurance to be offered for places and perils previously deemed too unremunerative and risky for traditional insurance to operate. But these abstractions have generated their own new sets of uncertainties.

Most prominently, parametric design inevitably leaves those insured holding 'basis risk'. This refers to the risk of a discrepancy between the measures and models that determine payouts, on the one hand, and events on the ground, on the other. Even traditional indemnity insurance carries some basis risk: those insured typically have some 'deductible' amount of losses they must self-fund first, and claims can be denied if losses were caused by a contractually-excluded event (Muir-Wood 2017). Indeed, traditional insurers regularly make legal recourse to carefully constructed contractual definitions of harm and limits to liability in order to avoid paying indemnities (e.g. Baker 1994).

But basis risk for parametric insurance is of a different nature. One-to-one indemnification for losses is never promised. Payout determinations can be made without the insurer conducting any on-the-ground loss assessment with insured parties. A great deal then rests on the accuracy of the measures and models selected as proxies. Yet insured parties are rarely familiar with how well these proxies correspond to their experience (or not), and often lack the actuarial skills to assess a contract's reliability. Compounding the problem of proxy accuracy, catastrophe insurance coverage poses a more general problem. Unlike insurance for more quotidian events, catastrophe insurance is a 'credence good', where the irregular and infrequent temporality of loss events makes it difficult for buyers to assess the quality of the product before purchase. Learning takes place after premiums have been paid, when those insured see how an actual contract performs in comparison to their expectations (Clarke and Wren-Lewis 2013).

\section{Drought insurance}

Several countries insured by the African Risk Capacity ${ }^{2}$ drought insurance programme have learned retrospectively about the limitations of the coverage they purchased. Organisationally housed within the African Union, ARC brings sovereign nations into a mutual insurance pool for drought protection, with backstopping 
by global reinsurers. ARC's design is routinely championed as a path-breaking example, leveraging satellite data and regional solidarity to finance drought disaster response (UNFCCC 2017). The risk pool is capitalised by participating countries' premiums, alongside interest-free equity from the UK and German development agencies. Payouts are triggered based on estimates of the number of droughtvulnerable people requiring relief, as modelled by ARC's proprietary software, Africa RiskView. If triggered, ARC payouts must be used to fund the member's pre-approved contingency plan for relief operations.

A great deal rests on the accuracy of the model's estimated number of droughtvulnerable people. Africa RiskView constructs a complex causal chain to arrive at this number. It feeds satellite-based rainfall estimates into agronomic models of reference crops; shortfalls are then compared with pre-existing analyses of food security and population vulnerability to generate an estimate of the maximum number of people affected by a drought event. Member countries customise their insurance contracts to trigger a payout when a certain threshold number is reached.

In 2015, Malawi became the first southern African country to join the ARC pool of seven total members, paying US $\$ 4.7$ million in premiums from its treasury for drought insurance cover. In March 2016, the Malawian government declared a drought emergency. Rains had failed at a critical time for the staple maize crop, and the stress was compounded by extremely high temperatures. Households' food stores and assets were already depleted by the previous season's droughts, floods and high food prices, stemming partly from an ongoing El Niño event (e-Pact 2017). In June, ARC announced that Malawi's drought insurance contract had not triggered a payout. Its model estimated the size of the drought-affected population at just 21,000 people. Meanwhile, a joint assessment by the government and aid organisations put the number at 6.5 million people (ActionAid 2017).

Though the biggest drivers of this staggering discrepancy are still subject to debate, poor data and poor model specification both played a part. Initially, ARC blamed the underestimate on the fact that Malawi had selected a long-cycle maize variety as the model's agronomic reference crop, while the majority of Malawi's farmers had recently switched to planting a short-cycle hybrid variety that was catastrophically damaged by cessation of rains after planting. Because the reference crop was chosen by government teams presumed to be knowledgeable about their country's agricultural sector and its vulnerabilities, ARC deflected responsibility for the discrepancy to the Malawian government. Yet a later ground-based survey and model assessment found that both short- and long-maturing varieties of maize suffered similar drought impacts, suggesting that the model would have performed poorly even with the correct reference crop (e-Pact 2017: 33-34). The likely greater problems lay in the model's parameters: it did not account for the impacts of high temperatures on plant evapotranspiration and water stress, or the timing of dry spells during a crop's growth cycle (ibid.). After seven months of consultations, donor pressure and international media scrutiny, ARC's Board of Directors formally approved a policy exception and agreed to disburse US $\$ 8.1$ million to resolve the 'Malawi crisis' (ARC Agency 2016). Nine months after the government's 
emergency declaration, Malawians finally received ARC-funded relief in the form of legumes for household consumption.

Though ARC adjusted its model following the Malawi crisis, its problems did not end there. Africa RiskView again did not trigger a payout for a 2017 drought in Mauritania, despite dire conditions on the ground. A ground-truthing team suggested the discrepancy stemmed from inaccurate rainfall data, poor assumptions in the agronomic model and the strikingly invalid assumption that farmers would have the resources to replant following failed rains (ARC Agency 2017). Again ARC's board approved an exception and made an extra-contractual payout (ARC Agency 2018).

\section{Pandemic bonds}

No such exceptions to policy were possible when the World Bank's first pandemic bond failed to trigger a payout in July 2019. That month, the World Health Organization declared the Ebola virus outbreak that began in 2018 in the eastern DRC a 'Public Health Emergency of International Concern' (WHO 2019). By this time, it was already the second largest Ebola outbreak in recorded history, responsible for more than 1,500 deaths.

Following donors' abysmally slow response to the 2014-2016 Ebola outbreak in West Africa, the World Bank developed the Pandemic Emergency Financing Facility in consultation with the WHO. The PEF is intended to disburse surge financing to enable rapid responses to 'infectious disease outbreaks before they take on pandemic proportions' (World Bank 2018a: 4). ${ }^{3}$ Unlike ARC, where countries must self-select into the risk pool and pay an insurance premium, the PEF coverage automatically applies to all countries eligible for assistance from the World Bank's International Development Association lending arm, without requiring any premium payment. ${ }^{4}$ While it includes a 'cash window' for early donor support, the PEF's signal innovation is an 'insurance window' that draws down private investments made in a US\$425 million catastrophe bond (Erikson 2019). An insurance payout for relief efforts is triggered if three major conditions are met: reports from the WHO confirm at least 250 total deaths; a third-party model deems rates of disease transmission to be growing over a sustained period and the disease spreads across borders resulting in at least 20 deaths in a second country (World Bank 2018a).

The requirement for geographical spread disqualified the Ebola epidemic in the DRC from triggering PEF's insurance window. Though several Ebola deaths were confirmed in Uganda and feared in Rwanda and Tanzania, the count never reached 20 in a second country. As medical anthropologist Susan Erikson (2019) notes, the PEF's emphasis on the transparency and exactitude of disease counts ignores the vastly uncertain conditions under which disease data are collected: often by freelance enumerators and irregularly paid health workers hired to travel vast distances in dangerous conditions, and possibly denied access to villages. Recent violent attacks on health workers in the DRC underscore the ongoing precarity of the counting enterprise. Nonetheless, so far, no one has alleged that the insurance window trigger 
conditions were actually met in the DRC and neighbouring countries, or that an error of measurement prevented a payout. Rather, the contractual criteria set a high enough bar - confirmed deaths and cross-border spread and growth rate - that it may well be the case that not all were met at the same time. It is impossible to know. Meanwhile, investors in the PEF catastrophe bond lost none of their principal, and continued to receive interest payments. Critics have heaped opprobrium on the World Bank for its role in designing the unscathed bond (Garrett 2019; Jonas 2019), and public health scholars suggested its conditions would have generated a payout for only two events since 2006 (Brim and Wenham 2019). Indeed the PEF bond did not trigger its US\$195 million payout for COVID-19 until late April 2020, when this chapter was already in press (World Bank 2020).

\section{Uncertain liability}

ARC's and PEF's recent experiences suggest new domains of uncertainty introduced by insurance tools. In Malawi, bad data and poor model specifications led ARC to underestimate the actual extent of drought and its impact on farmers. Rather than introducing automaticity and timeliness to drought relief funding, the ARC contract gave rise to dispute, blame and delay. In the DRC, the bond's activation criteria legally prevented the World Bank from drawing down investors' funds despite the raging epidemic (Erikson and Johnson 2020). Rather than delivering capital market funds for public health emergencies, the coverage gave rise to befuddlement and recrimination.

In both cases there is a political economy of basis risk and liability. Contractual structures designed to preserve tight control over payouts are necessary in order to secure reinsurance cover or capital market investments. Both reinsurers and investors demand surety that their capital will only be depleted under specific conditions. Firms model the likelihood of these conditions transpiring in order to price contracts, estimate total exposures and hedge portfolios. When basis risk events occur, reinsurers and investors are largely unaffected - although reinsurers may suffer reputational damage from being associated with a product that did not pay out when public opinion deems it should have.

Who then is liable? In Malawi and Mauritania, ARC's governing board eventually approved exceptions to policy to allow the compensatory payouts. In both cases, ARC's reinsurers did not object, because the payouts (US\$8.1 million and US $\$ 2.1$ million, respectively) were small enough that the reinsurance coverage was not activated. The funds came out of ARC's risk pool, co-owned by German and British government aid agencies and ARC's African member states. Ultimately, it was governments and their taxpayers who shouldered the exceptional payments.

Unlike ARC, PEF's catastrophe bond cannot permit post hoc exceptions, as it is legally bound by the terms of the prospectus circulated to investors. If an epidemic does not meet the bond's activation criteria, but still meets minimum epidemiological thresholds, governments or responding humanitarian agencies can request funds from the PEF's 'cash window', funded by German and Australian development aid (World Bank 2018b). It was this window that disbursed US $\$ 50$ million 
for the 2019 Ebola epidemic in the DRC, and was empty by the time COVID-19 emerged as a new threat in 2020. Again, it was governments and their taxpayers who shouldered the cash payments.

Indeed, there is a good argument to be made for wealthy governments bearing such costs. But this reflects a different political economy of liability than one in which capital from private reinsurers and investors is truly leveraged to narrow the 'global protection gap'. In the cases of ARC and PEF, the reinsurer and investor capital underwriting these products remained intact in the midst of severe droughts and a historic epidemic.

There are some cases when parametric tools fortunately work as advertised, such as a US\$22 million ARC payout to Senegal in November 2019. Yet models and triggers for sovereign parametric products thus far appear biased in favour of insurers. If basis risk errors were random, the number of 'downside' basis risk events should roughly equal the number of 'upside' events (when an index suggests conditions on the ground are worse than they actually are, potentially triggering an excessive payout). Yet there is little evidence of upside events. The number and variety of cases in which contracts misfire suggest that the turn towards parametric insurance products is not consistently reducing uncertainty for Southern governments, or reliably transferring it to the private sector. Rather, it may be redistributing the undesirable components of uncertainty as basis risk both to those insured and to donor governments, who bear the costs when parametric products fail to deliver protection.

While parametrics promise Southern government decision-makers coverage for a stated hazard, they also expose them to a new kind of risk. This, in the words of a senior risk modelling executive, is 'the toxic politics of basis risk' (Muir-Wood 2017). This is the political liability of spending scarce treasury funds to purchase a policy that does not pay out when the government expects it to, or when angry citizens think it should. If fear of basis risk drives enough decision-makers to remove their countries from a risk pool - as occurred with ARC following the Malawi crisis - this creates cascading doubts for other members about the long-term viability of the pool itself. Uncertainty proliferates.

\section{Technologies of humility?}

Given these challenges, one might ask whether it is possible to rescue the promise of insurance as a technique of mutual solidarity and sustainable risk-sharing. Can parametric insurance arrangements ever reliably reduce uncertainties and secure financing for disaster liabilities, as proponents hope? Or are they bound simply to pass uncertainties around?

It is possible to imagine insurance otherwise. Here, we might begin our reenvisioning with Jasanoff's (2003) proposal for new 'technologies of humility' in policy-making that complement and correct the hazards of technologies of hubris. Technologies of humility are 'institutionalized habits of thought that try to come to grips with the ragged fringes of human understanding - the unknown, the uncertain, the ambiguous, and the uncontrollable' (ibid.: 227). These habits of 
thought acknowledge areas of fundamental uncertainty, the possibility of unforeseen consequences and the need for plural viewpoints and collective learning. This epistemological disposition is a crucial corrective to technically complex modelling, which by its nature tends to minimise the significance of whatever falls outside its field of vision, and overstate the importance of whatever falls within it (ibid.: 239). Approaching parametric insurance products from the disposition of technological humility yields some unconventional ideas for re-imagining their design and function.

Jasanoff suggests four focusing questions we might use to cultivate technologies of humility. These are questions that technologies of hubris persistently avoid. Is the scope of the problem appropriately framed? Who is vulnerable? What are the distributive implications? And how should we learn from failure? Let us consider each in turn.

Framing: The framing of the 'global protection gap' suggests both a problem and a solution. If the problem is uninsured losses then the solution that follows is extending the reach of insurance tools to new hazards, new geographies and new domains of the economy. But, as the law of the instrument holds, 'to someone with a hammer, everything looks like a nail'. If the problems of uninsured losses and unassigned contingent liabilities are instead reframed as missing safety nets and absent social contracts, the fields of play suddenly become much larger. Questions of social protection and democratic governance come into view. Insurance can be put into perspective as only a modest and partial solution. Parametric products may or may not fulfil a need.

Attention to framing might also lead us to consider whether calling parametric products 'insurance' is cognitively useful, or instead misleading. Language shapes expectations. The term 'insurance' connotes a relationship of security and indemnification that parametric products expressly avoid. Calling parametric products insurance' may downplay the inevitable uncertainty and basis risk they contain. Describing them rather as 'derivatives' - financial products whose value is based on the behaviour of another underlying variable - would make these uncertainties more evident. At first glance, this might seem a counterintuitive suggestion: derivatives were notoriously implicated in the accumulation, packaging and trade of massive mortgage debts culminating in the global financial crisis of 2007-2010. Yet this experience arguably raised media and political awareness of their prevalence and the risks of their use. Unless or until parametric insurance products are systematically qualitycontrolled to track and ensure correspondence between indices and losses, they are essentially weather and environmental derivatives. Describing them as such might signal their limitations and prompt a healthy new degree of scrutiny over their use.

Vulnerability: We have already seen how the design of parametric products sometimes leaves those insured holding large basis risk. This is the chance that they will pay an insurance premium, experience a catastrophic event and then receive no payout according to contractual terms. Though basis risk can be reduced through careful design, it can never be eliminated. It must be accepted as a corollary of 
extending insurance arrangements to populations and locales not traditionally deemed insurable.

Who, then, is particularly vulnerable to such basis risk? Countries whose governments are willing to experiment with the imperfect coverage of parametric sovereign insurance contracts tend to be those whose marginal position in the global political economy compels them to accept a compromise on terms set by global insurers, investors and development banks. Those with limited technical and actuarial training are especially vulnerable, as they may not be able to assess fully the terms of the coverage offered, and thus may remain unaware of the basis risk their treasuries will retain. Building technologies of humility to address such vulnerability would minimally require transparent technical and actuarial analysis of competing options, advocacy on countries' behalf with insurance providers, and cultivation of regional or country-based networks of expertise. It is critical that such a data analytics-intensive technical role be played by parties without any financial or operational interests in a country's ultimate risk management choices, unlike in today's model, in which technical expertise flows from reinsurers, reinsurance brokers and the World Bank.

Distribution: An obvious question often monitored by donor institutions concerns the distribution of insurance payouts. This is in essence a question of auditing who receives payouts from insurance policies, and tracking the cost to distribute each dollar of aid via this channel as opposed to another, such as cash transfers (Jensen et al. 2017). Although it is indeed critical to understand this, a deeper question of distribution remains: where does the bulk of donor funds put into parametric insurance ultimately accrue? What is the likelihood of a given donor dollar being distributed (in cash or kind) to a vulnerable person, or being retained by an insurer or intermediary? When would a contract have paid out for past historical events? While historical calibration is often conducted for the purposes of pricing insurance contracts, this information is rarely made public, nor are payout frequencies (and their relative costs and trade-offs) subject to public deliberation. An approach promoting humility could mandate the standardised disclosure of these distributional arrangements and facilitate debates over the minimum criteria for publiclysubsidised coverage.

Learning: When technological innovations in insurance fail to live up to the expectations heaped upon them - as so many technologies inevitably do - a crucial question concerns what and how we can learn from these experiences. When predictive models misfire, blame and recrimination typically follow. The opacity or transparency with which insurance institutions review and revise models and data sources is a critical determinant for (re)building credibility among those insured and the public. But there will always be some degree of causal ambiguity, and competing explanations for failure will depend on actors' positions within the insurance relationship.

A better question, then, is not what institutions learn about the shortcomings of their models, but rather how basis risk events could galvanise the development 
of different fora for decision-making that would make parametric insurance more adaptive, context-dependent and responsive. This would require letting go of some of the persistent impulses towards control that led to the embrace of parametric insurance tools in the first place. We might imagine, for instance, fora for participatory deliberation among mutually insured parties about what should constitute a basis risk event, or what criteria should be used to reallocate inevitably limited indemnification funds to such cases. Such fora would need to be animated by a different model of trust than the asymmetric one that characterises typical insurerinsured relations, in which those who are insured are asked to place their trust in an insurer who expressly doubts the trustworthiness (or wisdom) of those being insured. Within participating countries, fora could be established in which civil servants, civil society organisations and beneficiaries themselves could deliberate over the inevitable trade-offs involved in their country's selection of particular contractual terms and triggers.

Some will object that this reorientation would undermine the entire ontological framework of insurance, based as it is on probabilistic calculation and objective payout criteria. Yet the history of insurance in mutuals, friendly societies (Van Leeuwen 2016; Ismay 2015) - and even commercial reinsurance (Jarzabkowski et al. 2015) demonstrates that more relational and contextual deployments of insurance are possible, and indeed were the norm for centuries. But these have typically been built on more extensive interpersonal ties and expectations of longer-enduring relationships, both between members of the risk pool and between insurer and insured.

Despite their promise to extend insurance security to new geographies and hazard domains, parametric insurance and 'insurance-like products' currently suffer from a legitimacy deficit due to the basis risk they transfer to those insured. Basis risk needs to be understood not simply as a problem of poor design, but as an existential political challenge to the framework of parametric insurance. If we are to salvage the value of parametric insurance as a solidaristic tool for coping with uncertainties, then we must approach the technology with a dose of humility. Parametric insurance could become a far more democratic tool of risk governance, building 'on people's legitimate expectations of equality, representation, fairness and public accountability' (Jasanoff 2010: 29). But this requires a radical openness to re-imagining its design and the constituencies to which it is accountable - and a willingness to relinquish the illusions of objective control at a distance.

\section{Notes}

1 The likes of which are proposed by Clarke and Dercon (2019).

2 www.africanriskcapacity.org.

3 However, anthropological accounts of Ebola's spread in West Africa suggest that funding shortfalls were far from the most significant factor in preventing the disease's containment (Erikson 2016; Wilkinson and Leach 2015).

4 In 2020, this included 76 countries, 39 of which were in Africa (http://ida.worldbank. org/about/borrowing-countries). 


\section{References}

ActionAid (2017) The Wrong Model for Resilience: How G7-Backed Drought Insurance Failed Malawi, and What We Must Learn From it, Johannesburg: ActionAid

African Risk Capacity Agency (2018) 'Report of the Sixth Session of the Conference of the Parties of the African Risk Capacity Agency, Nouakchott, Mauritania’, ARC/COP6/ D043.0103_18

— (2017) Technical Analysis of the Africa RiskView 2017 Customization for Mauritania, Johannesburg: African Risk Capacity Agency

- (2016) 'Malawi to Receive USD 8M Insurance Payout from African Risk Capacity', press release 14 November, Johannesburg: African Risk Capacity Agency

Baker, T. (1994) 'Constructing the Insurance Relationship: Sales Stories, Claims Stories, and Insurance Contract Damages’, Texas Law Review 72: 1395-1433

Brim, B. and Wenham, C. (2019) 'Pandemic Emergency Financing Facility: Struggling to Deliver on its Innovative Promise', The British Medical Journal 367: 15719

Clarke, D. and Dercon, S. (2019) Beyond Banking: Crisis Risk Finance and Development Insurance in IDA19, London: Center for Disaster Protection

— (2016) Dull Disasters: How Planning Ahead Will Make a Difference, Oxford: Oxford University Press

Clarke, D. and Wren-Lewis, L. (2013) Learning from Lemons: The Role of Government in Index Insurance for Individuals, Paris: Fondation pour les Études et Recherches sur le Développement International

Cummins,J.D. and Mahul, O. (2009) Catastrophe Risk Financing in Developing Countries: Principles for Public Intervention, Washington, DC: The World Bank

Dunn, E.C. (2012) 'The Chaos of Humanitarian Aid: Adhocracy in the Republic of Georgia', Humanity: An International Journal of Human Rights, Humanitarianism, and Development 3.1: $1-23$

e-Pact (2017) 'Independent Evaluation of the African Risk Capacity (ARC) Formative Phase 1 Report', Oxford: e-Pact Consortium: Oxford Policy Management and Itad

Erikson, S. (2019) 'Global Health Futures? Reckoning with a Pandemic Bond', Medicine Anthropology Theory 6.3: 77-108

- (2016) 'Money Matters: Ebola Bonds and Other Migrating Models of Humanitarian Finance', in M. Böckenförde, N. Krupke and P. Michaelis (eds) Reflections on Global Cooperation and Migration, Duisberg: Käte Hamburger Kolleg/Centre for Global Cooperation Research

Erikson, S. and Johnson, L. (2020) 'Will Financial Innovation Transform Pandemic Response?', The Lancet Infections Diseases 20.5: 529-530

Garrett, L. (2019) 'The World Bank has the Money to Fight Ebola but Won't Use It', Foreign Policy, 22 July

Hess, U., Richter, K. and Stoppa, A. (2002) 'Weather Risk Management for Agriculture and Agri-Business In Developing Countries', in R. Dischel (ed) Climate Risk and the Weather Market: Financial Risk Management with Weather Hedges, London: Risk Books

Ismay, P. (2015) 'Between Providence and Risk: Odd Fellows, Benevolence and the Social Limits of Actuarial Science, 1820s-1880s', Past \& Present 226.1: 115-147

Jarzabkowski, P., Bednarek, R. and Spee, P. (2015) Making a Market for Acts of God: The Practice of Risk-Trading in The Global Reinsurance Industry, Oxford: Oxford University Press

Jasanoff, S. (2010) 'Beyond Calculation: A Democratic Response to Risk', in A. Lakoff (ed) Disaster and the Politics of Intervention, New York: Columbia/Social Science Research Council: $14-40$ 
(2003) 'Technologies of Humility: Citizen Participation in Governing Science', Minerva 41: 223-244

Jensen, N.D., Barrett, C.B. and Mude, A.G. (2017) 'Cash Transfers and Index Insurance: A Comparative Impact Analysis from Northern Kenya', Journal of Development Economics 129: 14-28

Jonas, O. (2019) 'Pandemic Bonds: Designed to Fail in Ebola', Nature 572: 285

Lloyd's (2018) A World at Risk: Closing the Insurance Gap, London: Lloyd's of London

Mawdsley, E. (2015) 'DFID, the Private Sector and the Re-Centring of an Economic Growth Agenda in International Development', Global Society 29.3: 339-358

Muir-Wood, R. (2017) 'The Politics of Basis Risk', RMS Blog, Newark: Risk Management Solutions

Sauer, N. (2019) ‘Mozambique "Faces Climate Debt Trap” as Cyclone Kenneth Follows Idai', Climate Home News, 26 April

Swiss Reinsurance (2015) Underinsurance of Property Risks: Closing the Gap, Sigma 5/2015, Zürich: Swiss Reinsurance

UN Framework Convention on Climate Change (2017) Compendium on Comprehensive Risk Management Approaches, Bonn: UN Framework Convention on Climate Change

Van Leeuwen, M.H. (2016) Mutual Insurance 1550-2015: From Guild Welfare and Friendly Societies to Contemporary Micro-Insurers, London: Palgrave Macmillan

Wilkinson, A. and Leach, M. (2015) 'Briefing: Ebola - Myths, Realities, and Structural Violence', African Affairs 114.454: 136-148

World Bank (2018a) Pandemic Emergency Financing Facility Operations Manual, Washington, DC: The World Bank Group

— (2018b) 'World Bank Group's Pandemic Emergency Financing Facility Welcomes Australia as New Donor', press release 21 June, Washington, DC: The World Bank Group - (2015) 'Pacific Catastrophe Risk Insurance Pilot: From Design to Implementation Some Lessons Learned', Washington, DC: The World Bank Group

- (2020) 'PEF Allocates US $\$ 195$ Million to More than 60 Countries to Fight COVID19', press release 27 April, Washington, DC: The World Bank Group

World Health Organization (2019) 'Ebola Outbreak in the Democratic Republic of the Congo Declared a Public Health Emergency of International Concern', press release 17 July, Geneva: World Health Organization 